\title{
“PAU QUE NASCE TORTO NUNCA SE ENDIREITA?" UMA PROBLEMATIZAÇÃO DA NATURALIZAÇÃO DA VIOLÊNCIA ESCOLAR
}

\author{
“CAN A LEOPARD NOT CHANGE ITS SPOTS?” PROBLEMATIZING \\ NATURALIZED VIOLENCE IN SCHOOLS
}

\author{
“¿ÁRBOL QUE NACE TORCIDO, JAMÁS SU TRONCO ENDEREZA?” \\ PROBLEMÁTICAS DE LA NATURALIZACIÓN DE VIOLENCIA ESCOLAR
}

\author{
Aldenor Batista da Silva Junior ${ }^{\mathrm{i}}$ \\ Sonia da Cunha Urt ${ }^{\text {ii }}$
}

\begin{abstract}
Resumo: Em ambientes sociais, os sujeitos experimentam coalizões que colocam em prova o desafio da diversidade e a compreensão do outro. É ígneo em nossas práticas sociais a necessidade do uso da força e nas variadas vicissitudes em que se apresenta, pode-se chegar naquilo que chamamos de violência. Sendo a violência que chega até a escola, pouco conhecida e enfrentada, torna-se desencadeante de problemas relacionais e perturbadora do desenvolvimento da aprendizagem. Desse modo, percebemos cada vez mais a necessidade de compreender a sua originalidade e as formas como esta é compreendida. O presente estudo inicia-se como título 'Pau que Nasce Torto nunca se endireita?', dado este nome, compreendemos que para entender a sociedade devemos dar atenção aos provérbios presentes dentro de um determinado contexto cultural, pois estes, também carregam ideias, argumentos, dialoga e relaciona-se com perspectivas teóricas e leituras da realidade social. Este trabalho é fruto do levantamento de produções, leituras e discussões realizadas no grupo de estudos em Educação e Psicologia (GEPPE) em Mato Grosso do Sul-Brasil durante a pesquisa intitulada "Violência e Preconceito na Escola", com financiamento do MEC. O estudo direcionou-se em torno da Psicologia Histórico cultural de Vigotsky e seus interlocutores baseada materialismo histórico dialético como eixo para a análise da constituição do sujeito, a violência que acontece na sociedade e consequentemente na escola. Acredita-se que essa base teórica contribui para o estudo da estrutura econômica e social que geram as condições para a violência na sociedade e, por consequência, na escola, enquanto instituição social. Entende-se que a violência não se passa por via biológica, muito menos, descolada dos contextos sociais e históricos que a produz. $\mathrm{Na}$ escola, viralizou-se uma perspectiva idealizada de que as soluções estariam centradas nas particularidades, distanciando-se das universalidades e da objetividade. Neste trabalho, foi possível observar a articulação entre a lógica dos entendimentos que se tem acerca da violência e a implicação destes, observando por meio dos estudos levantados, o quanto que as condições objetivas presentes são percebidas de forma segmentada, influenciando na atuação do psicólogo e dos outros educadores frente aos casos escolares de violência.
\end{abstract}

Abstract: In social environments, subjects experience coalitions that challenge diversity and the understanding of others. The need for using force and its various vicissitudes are fiery in daily social practices, becoming what it is called violence. Violence within schools' daily life is little known and addressed triggering relational problems that hamper the learning development. Thus, understanding from where and how violence in schools stems is of paramount importance. By proposing the title 'can a leopard not change its spots?', we mean that to understand the society we must pay attention to the proverbs present within a given cultural context as it also carries ideas, arguments, dialogues and relates to theoretical perspectives and readings of social reality. This work comprises a review of scientific productions, readings and discussions carried out by the study group on Education and Psychology (GEPPE) in Mato Grosso do Sul (Brazil) during the research entitled "violence and prejudice at school", funded by the Ministry of Education (MEC Brazil). The study focused on the Cultural-Historical Psychology of Vigotsky and his interlocutors based on dialectical historical 
materialism as an axis for the analysis of the constitution of the subject, violence in society and consequently in school. This theoretical basis may contribute to the study on the economic and social structure that generate the conditions for violent behavior in society and consequently in school, as a social institution. Neither violence is biologically explained, nor is it dissociated from social and historical contexts. In schools, idealized solutions focused on particularities went viral, ignoring universalities and objectivity. In this work, we observed the articulation between the logical understanding of violence and their implications. It was also noticed that the objective conditions are perceived fractionally influencing the psychologist's performance and other educators in school violence cases.

Resumen: En entornos sociales, los sujetos experimentan coaliciones que ponen a prueba el desafío de la diversidad y la comprensión del otro. Es feroz en nuestras prácticas sociales la necesidad de usar la fuerza y en las diversas vicisitudes en que se presenta, podemos llegar a lo que llamamos violencia. Dado que la violencia que llega a la escuela, poco conocida y enfrentada, se convierte en desencadenante de problemas relacionales y perturba el desarrollo del aprendizaje. Por lo tanto, percibimos cada vez más la necesidad de comprender su originalidad y las formas en que se entiende. El presente estudio comienza con el título ‘cárbol que nace torcido, jamás su tronco endereza?’. Dado este nombre, entendemos que para entender a la sociedad debemos prestar atención a los proverbios presentes dentro de un contexto cultural dado, ya que estos también llevan ideas, argumentos, dialoga y se relaciona con perspectivas teóricas y lecturas de la realidad social. Este trabajo es el resultado de una encuesta de producciones, lecturas y debates llevada a cabo en el grupo de estudio sobre Educación y Psicología (GEPPE) en Mato Grosso do Sul-Brasil durante la investigación titulada "Violencia y prejuicio en la escuela", con fondos del MEC. El estudio se centró en la Psicología Histórica Cultural de Vigotsky y sus interlocutores basados en el materialismo histórico dialéctico como eje para el análisis de la constitución del sujeto, la violencia que ocurre en la sociedad y, en consecuencia, en la escuela. Se cree que esta base teórica contribuye al estudio de la estructura económica y social que genera las condiciones para la violencia en la sociedad y, en consecuencia, en la escuela, como institución social. Se entiende que la violencia no ocurre a través de medios biológicos, mucho menos separados de los contextos sociales e históricos que la producen. En la escuela, se hizo viral una perspectiva idealizada de que las soluciones se centrarían en las particularidades, alejándose de las universalidades y la objetividad. En este trabajo, fue posible observar la articulación entre la lógica de los entendimientos sobre la violencia y sus implicaciones, observando a través de los estudios planteados, cuánto se perciben las condiciones objetivas presentes de forma segmentada, influyendo en el desempeño del psicólogo. y otros educadores frente a casos de violencia escolar.

Palavras-chaves: Violência. Violência na Escola. Naturalização. Psicologia Histórico Cultural. Keywords: Violence. Violence in School. Naturalization. Cultural-Historical Psychology.

Palabras clave: Violencia. Violencia en la escuela. Naturalización. Psicología Histórica Cultural.

\section{INTRODUÇÃO}

As relações conflitivas e a violência sempre estiveram presentes na vida social e não se extinguirão com simplórias concepções e práticas a seu respeito. Em ambientes sociais, os sujeitos experimentam coalizões que colocam em prova o desafio da diversidade e a consociação no processo de compreensão do outro. É ígneo em nossas práticas sociais a necessidade do uso da força e nas variadas vicissitudes em que se apresenta pode-se chegar naquilo que chamamos de violência.

No cotidiano escolar, ocorrem uma série de mediações entre alunos e seus professores, colegas de trabalho e pais. As vivências destas interações podem desencadear 
situações de conflito onde a violência pode vir a ser configurada. Sendo a violência que chega até a escola, tratada de forma naturalizada, pouco conhecida e enfrentada, torna-se desencadeante de problemas relacionais e perturbadora do desenvolvimento da aprendizagem.

Parte-se aqui, neste trabalho, de uma compreensão dialética influenciada por Hegel e que teve seguimento por Marx de que 'nem tudo que parece é' para que uma série de especulações formuladas a partir de questionamentos permitam refletir os fatos e as relações violentas presentes nas situações concretas no interior do ambiente escolar.

Pondera-se neste momento, por meio do significado que revela a expressão popular: 'Pau que nasce torto nunca se endireita', para compreender as experiências de violência consideradas de cunho biológico e algumas formas de 'endireitamento' elegidas pela escola que perpetuam a atribuição individualizada para situações que ocorrem dentro de um contexto mais amplo e social, e desta forma ilustrar que há contrariedades que estão latentes e/ou manifestas na realidade escolar.

As reflexões aqui apresentadas, são fruto da pesquisa intitulada Violência e Preconceito na Escola', com financiamento do Ministério da Educação (MEC) ${ }^{1}$ e com a parceria entre instituições nacionais de Psicologia ${ }^{2}$ e dez Universidades Federais distribuídas pelas cinco regiões do país ${ }^{3}$.

O presente trabalho tem como título 'Pau que Nasce Torto nunca se endireita? Uma Problematização dos Casos de Violência na Escola', dado este nome, compreendemos que para entender a sociedade devemos dar atenção aos provérbios presentes dentro de um determinado contexto cultural, pois estes, também carregam ideias, argumentos, dialoga e relaciona-se com perspectivas teóricas e leituras da realidade social.

O texto espera contribuir para a compreensão da constituição do sujeito e da violência acometida em sociedade em um campo interdisciplinar, sem reduzir as referências ao campo da Psicologia ou da Educação e, menos ainda, somente ao âmbito da escola. Cabe apontar, que o propósito é colaborar para a construção de um marco mais amplo que leve a

\footnotetext{
1 Fórum de Entidades Nacionais da Psicologia Brasileira - FENPB; Associação Brasileira de Ensino de Psicologia - ABEP; Federação Nacional dos Sindicatos de Psicólogos - FENAPSI; Associação Brasileira de Psicologia Escolar e Educacional ABRAPEE e Conselho Federal de Psicologia - CFP.

${ }^{2}$ Região Norte - UFPA e UFAM; Região Nordeste - UFPE e UFBA; Região Centro Oeste - UFMT (gestora) e UFMS; Região Sudeste - UFU e UFRJ e Região Sul - UFRGS - UFSC.

${ }^{3}$ Realizada pela equipe de pesquisa formada por docentes, discentes dos mestrados de Educação e de Psicologia e discentes da graduação do curso de Psicologia da Universidade Federal de Mato Grosso do Sul, sob a coordenação da Profa. Dra. Sônia da Cunha Urt.
} 
reflexão nos processos educativos e a violência, considerando a diversidade de contextos sociais e culturais que este se manifesta.

\section{A ViolênCia e a SuA Constituição}

A convivência nas escolas gera uma crescente preocupação social e educacional devido ao aumento da visibilidade dos atos violentos. Não me arrisco a dizer que agora existe mais violência do que há algumas décadas atrás, tampouco afirmar que a violência aumentou na sua proporção em toda a sociedade. Será que nos recordamos que a história social é carregada de atos de violência?

Vivemos imersos em diversos agrupamentos sociais. Ao longo da nossa vida, transitamos por diferentes grupos, dos mais básicos, como a família nuclear e extensiva, aos mais distantes, como as organizações escolares e a sociedade. Onde quer que estejamos, qualquer que seja o momento de nossa vida, estamos sempre nos afrontando com o fato de pertencermos a unidades e coletivos sociais, de diferentes manifestações. Ou seja, nunca estamos sozinhos, isolados ou fora de um contexto social.

A escola como um dos ambientes socializadores do indivíduo, não deixa de ser afetada pelas relações de dominação e poder, geradoras de conflitos. As relações estabelecidas dentro do ambiente escolar entre pares e grupos podem ocasionar uma série de interações resultantes de conflitos entre atores escolares (professor, diretor, aluno, coordenador e pessoal do apoio) e a comunidade exterior ao espaço escolar.

Levando em consideração a ideia de que "o desenvolvimento psicológico dos homens é parte do desenvolvimento geral de nossa espécie" (VIGOTSKY, 1991, p.69), considera-se que entender as problemáticas da sociedade, deve ir além de uma abordagem naturalizante, que compreende o homem enfocado somente no biológico. Os fenômenos, não devem ser tratados por uma lógica abstrata de pensamento filosófico, mas como fenômenos concretos historicamente vividos (VIGOTSKI, 1999). Deve-se aproximar de uma abordagem dialética, que busca a compreensão do movimento histórico da humanidade.

Nesta abordagem, o sujeito é constituído por meio da relação dialética envolvendo os processos de apropriação e objetivação no seu contexto cultural e dependerá das condições objetivas de vida e das atividades transformadoras em sociedade. O indivíduo só existe em uma trama de relações, sendo membro de um grupo social no qual ele é influenciado durante o seu desenvolvimento histórico. A formação da sua personalidade e o modo como manifesta o seu comportamento depende de uma evolução social cujas determinações são feitas pelo social (VIGOTSKY, 1930). 
O indivíduo é concreto, histórico, social e cultural. Aquele no qual sua subjetividade é modificada através das coalizações sociais e culturais que se estabelecem no decorrer da constituição de sua vida. Dessa forma, por meio da apropriação das condições objetivas experimentadas na cultura, o indivíduo acaba sendo sensibilizado e desenvolve formas de refletir e se comportar em sociedade, adquirindo práticas de preconceito e violência.

A violência que o homem manifesta, passa por um processo lento de constituição, que vai desde o estágio de preparação biológica, chamado de hominização, aparato que coloca o homem em movimento e com capacidade de aprender, à formação da humanização, que é determinado pelos instrumentos e signos influenciados e apreendidos por meio do trabalho e da sociedade. Repetidas vezes, tenta-se sujeitar a explicação deste as leis biológicas transmitidas hereditariamente, porém, esta torna-se insuficiente para explicar a complexidade que o humano apresenta.

A violência é um atributo humano que só é possível pela presença da agressividade. A violência humana tem um apoio biológico integrado à vida psíquica através das pulsões primárias da agressividade que impelem a ação e está condicionada por variados determinantes sociais (MALO, 1998). A sociedade na qual estamos inseridos é violação constante da natureza, ou seja, dos processos biológicos. A humanização da natureza é um processo no qual o homem impõe uma lei estranha a ela, uma lei humana que força ou violenta sua regulação natural (VÁZQUEZ, 1980).

A genética humana, apesar de ser responsável pela a criação da matéria prima de nós seres vivos, por si só, não dá conta de uma diversidade de formas de vida e expressão.

O reducionismo das ciências naturais, acaba por conhecer a natureza unilateralmente, os aspectos relacionados a sociabilidade humana, todavia, acabam sendo ignorados em suas compreensões da realidade. A objetividade aparente tratada pelo modo de pensar científico, facilmente dissolve as relações sociais em fatores parcialmente físicos ou parcialmente biológicos (KURZ, 1996).

A violência que se exerce sobre um corpo não se detém nele, mas na sua consciência, seu verdadeiro objeto não é o homem como um ser natural, físico, como um mero ser dotado de um corpo, e sim, como um ser social, que em sua condição de sujeito, acaba sendo determinado por relações econômicas, sociais e políticas que encarnam e cristalizam em determinadas instituições e relações sociais (VÁZQUEZ, 1980). O homem é constituído pelo próprio homem.

A constituição do sujeito acontece em um processo socialmente construído, em um campo de inter-relações subjetivas configurado como um lugar de encontro, confronto e de 
negociações entre o eu e o outro (MOLON, 2011). O eu, se constitui naquilo que o outro e o sistema social no qual pertence, o possibilita ser. Dito de outra forma, os processos de desenvolvimento do indivíduo, aparecem primeiramente em um nível coletivo/social para depois ser interiorizado por ele.

O fenômeno da violência é culturalmente construído a partir da internalização de um conjunto de sentidos e significados. Por este motivo, defini-lo exige uma análise cuidadosa, pois, de acordo com os dizeres de Vigotski (2003, p. 76), "toda definição é uma restrição, ou seja, um enfoque parcial e unilateral do objeto". Sendo necessário, buscar seu entendimento junto aos sujeitos em seu contexto cultural, social e histórico, permitindo captar suas interpretações da realidade social, os significados que atribuem e os símbolos que produzem (KOTTAK, 2002).

Chauí conceitua a violência, além do uso da agressão física, ela aponta que este fenômeno se caracteriza como "um ato de brutalidade, sevícia e abuso físico e/ou psíquico contra alguém e caracteriza relações intersubjetivas e sociais definidas pela opressão e intimidação, pelo medo e pelo terror" (2005, p. 342), produzidas pela sociedade em relação às normas, leis, regras e hábitos culturais que estabelecem para conservar a violência e garantir a desigualdade social e pela perpetuação por parte dos indivíduos para uns com os outros.

Através da apropriação das condições objetivas experimentadas na cultura, o indivíduo acaba sendo sensibilizado e desenvolve formas de refletir e se comportar em sociedade, adquirindo práticas de preconceito e violência. A violência não é algo que está presente no aparato biológico do indivíduo desde o seu nascimento, mas um conjunto de símbolos e significados que foram transmitidos pelo contexto social e cultural que circunda o sujeito. Em consonância com este pressuposto, Mariana Costa, nos ajuda a pensar os estudos de Vàzquez no entendimento da violência.

A compreensão da violência como tarefa da Psicologia nos escritos de Vázquez (2008) nos instrumentaliza a teorização e também a prática ao postular que, quando a violência é divorciada da sua raiz objetiva e econômica-social, permite-se que a atenção esteja voltada para a própria violência e não para o sistema que a engendra. Perde-se de vista que a violência vivida diretamente representa a superfície dos fatos e é a expressão de uma violência mais profunda, que é a condição de exploração do homem pelo homem, fundante do capitalismo - o que nos encaminha a afirmá-lo como estruturalmente violento. $\mathrm{O}$ autor conclui disso que a violência só será superada em um modo de organização para a produção que se paute no trabalho humanizador, coletivo, que invista na formação humana e não na cumulação de capital que, por sua vez, requer a pauperização da imensa maioria da população (2008 apud COSTA, 2014, p. 29). 
Nesse sentido, é válida a importância de estudar a violência a partir do contexto social, econômico, cultural e político da sociedade (PLACCO et al., 2002). No mesmo raciocínio, Frederico Engels pensa que "estão sempre e em toda parte, as condições econômicas e os recursos de poder que estão disponíveis para ajudar a violência ter sucesso sem que ela deixe de ser violência" (1986, p.150).

Nesse sentido, a violência, mesmo que possa parecer um fenômeno individual, não permanece restrita apenas aos indivíduos que violentam ou são violentados, pois eles são seres sociais, partícipes em processos sociais reconstruídos em dadas condições históricas (CARVALHO; BARROCO, 2017, p.142).

Em apontamentos realizados por Lozano, Marx reconhece que a formação do capitalismo só foi possível mediante uma série de atos violentos (LOZANO, 1998). O capitalismo recorreu há várias condições econômicas, sociais, históricas e culturais prévias que estiveram vinculadas a violência desde o regime feudal, como: A colonização e a venda de escravos, as guerras entre os senhores feudais na disputa por terras e a troca dessas terras por dinheiro, a exploração dos meios de produção de grandes grupos de homens que foram lançados no mercado de trabalho como indivíduos livres e também, as medidas coercitivas que se utilizam nas cidades enquanto nestas não existiam as possibilidades de assimilar as forças de trabalho (ANDERY, et al. 2012). Em continuação a essa constatação, reafirma-se por Novais (1979), que o antigo regime [...] permitiu a formação e cristalização da etapa mercantil do capitalismo [...] (p. 62-63).

Em um campo de luta entre as classes, que origina e dá sustentação ao sistema capitalista, foram reproduzidos e produzidos vínculos explorativos, de oposição e rivalidade, resultando na violência que está presente no contexto social e no ambiente escolar.

O homem não nasce humanizado, ele precisa conquistar esta condição na batalha que trava diariamente em busca da sobrevivência, ou seja, um comportamento violento não é naturalmente violento, pois nem o homem é naturalmente humanizado desde o nascimento (BARROCO; CARVALHO, 2017, p. 143).

A violência não pode ser isolada como uma causa pura, mas como uma consequência das condições econômicas (LOZANO, 1998). O lugar e a forma da violência estão condicionados pela sua função no processo econômico e dentro deste sistema, que se perpetua e desenvolve novos setores específicos da violência, como a violência na escola.

E se percebemos a dura e longa caminhada do tempo, que chamamos de história, vemos que a violência não só persiste de uma vez para outra, e de uma sociedade para outra, mas que sua presença se torna esmagadora 
nessas conmoções históricas o que chamamos conquistas, colonizações, guerras ou revoluções. E não só aparece como um tambor balanço, servindo relações de dominação e exploração ou tentativas de libertação e tornando-se independente deles, mas também fazendo com que cresçam, surda e silenciosamente, a árvore do sofrimento na vida cotidiana (VÁZQUEZ, 1998, p. 9).

A partir de sua inserção no mundo e da consequente internalização dos processos culturais, o sujeito carrega uma estrutura social. Uma série de valores e significados da classe dominante, que não são questionados e sucedem, através de uma combinação de elementos, em manifestações de violência. $\quad$ Este fenômeno psicossocial, embora presente em contextos onde ocorre o processo de escolarização, acaba-se por naturalizá-lo.

\section{O Processo de Naturalização e a LegitimaÇão da ViolênCia na}

\section{ESCOLA}

As necessidades do sistema capitalista impõem a passividade e a adaptação nas pessoas para instalar seus ganhos e vantagens. A essa situação de imposição sobre a sociedade, entendemos que,

Para o capitalismo, o controle social é um aspecto primordial para atender as demandas do mercado. Assim, controlar o comportamento dos indivíduos ultrapassa a necessidade superficial de atender aos problemas de comportamento e aprendizagem dos alunos (SUZUKI, 2012, p.160161).

Diante deste cenário, muitas vezes acaba-se correndo o risco de individualizar e segmentar o fenômeno da violência, atribuindo ao indivíduo isolado, à sua genética e/ou a problemas de cunho psicológico, a responsabilidade por ações violentas, seja na sociedade ou em determinada instituição, como a escola.

Fica evidente para muitos que a indisciplina e a violência escolar vêm afetando negativamente o processo de escolarização e apropriação dos conhecimentos científicos pelos alunos, porém a escola acaba, em muitas situações, por atribuir a causa destes problemas ao fator biológico. Atribuindo os problemas de insucesso nas atribuições escolares e a violência ao viés orgânico, a escola permite a invasão da ciência médica para explicar e resolver ditos problemas de aprendizagem e comportamento (SUZUKI; LEONARDO; LEAL, 2017). Medica-se na tentativa de dar fim aos problemas que se produziram dentro de uma estrutura social mais ampla e no cotidiano pedagógico. 
[...] a ampliação crescente do trabalho de intervenção da medicina na vida das pessoas, passando para a alçada médica, inclusive, problemas claramente determinados pela forma de ser da sociedade, no interesse de se manter o status quo (por exemplo, escamoteando os conflitos inerentes às relações capital-trabalho) (BARROS, 1983, p. 378).

A concorrência universal imposta pelo capitalismo entre os indivíduos, grupos sociais e nações, do modo como resultou o funcionamento capitalista, ganhou cada vez mais corpo e espaço de interpretações biológicas com suporte em ideologias "científicas" centradas neste foco. Diante desta constatação, acoberta-se as contradições sociais da modernidade sob o manto de necessidades naturais (KURZ, 1996).

De acordo com Facci (2004), o fato de culpabilizar um só envolvido no processo de não aprendizagem escolar resulta em uma explicação feita de forma simples e orientada por questões ideológicas que permeiam os pretextos neoliberais, que desconsideram os fatores sociais envolvidos na complexidade em que é produzido o fracasso escolar. De forma natural e focalizado unicamente em práticas que individualizam, essas explicações, concentram a ideia de que as crianças, os jovens e os adolescentes são vítimas de suas próprias incapacidades diante do aprendizado, sem considerar uma série de fatores externos que envolvem o processo. Esta explicação também se estende como uma justificativa para as diversas mazelas sociais possibilitadas pelo capitalismo, como a pobreza, a desigualdade, e outras (FACCI, 2004).

Outro exemplo de naturalização, é a situação ocorrida em Mato Grosso do Sul, que coloca em pauta o Projeto de Lei n. ${ }^{o}$ 219/2015 - "Lei Harfouche" - que dispõe sobre a implementação de atividades com fins educativos para reparar danos causados no ambiente escolar na Rede Pública Estadual do Estado de Mato Grosso do Sul e dá outras providências para os casos de violência na escola (BRASIL, 2015). No artigo $1^{\circ}$ aponta que,

Ficam os estabelecimentos da rede estadual de ensino obrigados a executar a aplicação de atividades com fins educativos como penalidade posterior à advertência verbal ou escrita.

Dentro da proposta de lei indica-se que a mesma deve ser atribuída somente aos alunos, porém, aos que convivem e estudam os meandros que são vivenciados no ambiente escolar, sabem que a violência acontece em todos os tipos de relação, seja ela aluno-professor, professor-professor, aluno-aluno, gestão-aluno, gestão-professor, pai/mãe- professor e todas as outras combinações interativas que cabem no relacionar dentro de instituição educativa. 
Caso o projeto seja aprovado, a instituição fica responsável por lidar com os casos de indisciplina de maneira punitiva. Porém, a realidade escolar nos mostra que a operacionalização e a decisão sobre quais medidas e como elas devem ser tomadas frente aos casos, acabam passando por formas centralizadoras e precipitadas de decisão e por concepções ideológicas que orientam práticas segregadoras, preconceituosas e perversas.

Pensamos que, mais do que identificar as características individuais dos atores escolares que contribuem para a violência na escola, temos que criar espaços para compreender os contextos e os determinantes sociais que colabora para o seu aparecimento. E partindo desta premissa, promover a construção efetiva de propostas educacionais coletivas no interior da escola, na condição de comunidade escolar.

As práticas desenvolvidas dentro da escola, em muitos momentos podem por validar e reproduzir o pensamento 'categorizante', 'estigmatizante', 'culpabilizador', 'alienado' e 'patologizante' sobre o aluno, principalmente, e sobre outros atores escolares. Como exemplo quando um aluno 'problema' é retirado da sala de aula para realizar atendimentos que em muitos momentos ‘psicologizam' e 'moralizam' o sujeito avaliado, não refletindo o contexto e os determinantes sociais.

O sujeito retirado de sala de aula individualmente tende a sofrer categorizações e ofensas dos demais colegas da escola e muitas vezes, dos próprios educandos. Esta situação, quando não trabalhada e refletida individualmente pelos profissionais e coletivamente com a comunidade escolar, ao invés de se tornar uma oportunidade de desenvolvimento de competências, acaba por sujeitar o indivíduo ao constrangimento, reproduzir a exclusão e em alguns momentos, afastar a comunidade escolar de oportunidades de crescimento e desenvolvimento pessoal.

Acreditamos demonstrar que categorizar, castigar e estigmatizar o aluno, não é a melhor forma de enfrentar a problemática que afeta a escola e nem traz grandes benefícios aos envolvidos na situação de conflito. Somente um compromisso genuíno diante da situação, buscando envolvimento e desenvolvimento de estratégias por todos os atores da escola envolvidos no processo e que possa refletir a realidade social e individual, é que conseguimos alcançar os objetivos propostos. Devemos lembrar que muitas vezes os educadores esperam o aluno 'ideal', daquele que tem que apresentar formas de se relacionar diferentes daquela que ele viveu em suas condições sociais, ao invés de possibilitar a construção de novos sentidos pessoais para que todos possam refletir e reconstruir a sua subjetividade. 
As queixas escolares sobre conflitos interpessoais e comportamentos agressivos resultando em agressões físicas, psicológicas e verbais entre alunos, professores, pais e demais colaboradores, são frequentes. A escola é um espaço onde aparecem várias formas de expressão social, portanto, é um local propício para o aparecimento e desenvolvimento de afetos, emoções e sentimentos que em algum momento podem produzir conflitos resultantes de violências que necessitem de soluções efetivas.

Diante desta realidade, percebe-se a necessidade de que medidas sejam tomadas para restaurar a relação interpessoal, possibilitando que essa situação de conflito não venha se tornar um ato de violência ou dê continuidade à dinâmica de violência (SOUZA; SILVA, 2006), que está presente na vida social e se manifesta no espaço escolar.

\section{CONSIDERAÇÕES FINAIS}

A escola como uma das instituições responsáveis pelo viver em sociedade, deve ocupar-se da sua funcionalidade social para que os eventos de violência ocorridos dentro do seu espaço sejam enfrentados através de ações, projetos e propostas que visam o desenvolvimento integral do indivíduo. É necessário atender a todas as dimensões do desenvolvimento humano e criar um meio que potencialize as capacidades e habilidades dos sujeitos que fazem parte da escola.

A criação de mecanismos de superação das condições de violência impostas às relações sociais, criando processos de desnaturalização, é de extrema importância para o meio social e para a diminuição da violência através de práxis transformadoras. Deve-se compreender o fenômeno pelas vias da multiplicidade.

$\mathrm{Na}$ busca por compreender a complexa temática da violência escolar, nos preocupamos em esclarecer sobre a formação da violência dentro de um contexto que é social e histórico. Claro que algumas questões abordadas neste estudo requerem aprofundamento, porém, com este exercício espera-se que abra um campo de possibilidades para a desnaturalização e a não-individualização do fenômeno da violência sejam estabelecidas e que novas perspectivas para o fortalecimento e proposição de programas e de políticas públicas voltadas para o enfrentamento da violência na escola sejam encontradas.

\section{REFERÊNCIAS}

KURZ, R. A Biologização do Social: O Mundo Sofre Novo Desencantamento. 1996. Disponível em : <http://www.obeco-online.org/rkurz27.htm> 
ANDERY, M. A. P. A. et al. Do Feudalismo ao Capitalismo: Uma Longa Transição.In: 2012.

Para compreender a ciência - uma perspectiva histórica. São Paulo: Garamond.

BARROS, J. A. C. Estratégias mercadológicas da indústria farmacêutica e o consumo de medicamentos. Revista Saúde Pública, São Paulo, v. 17, n. 5 p. 377-386. 1983.

BARROCO, SMS.; CARVALHO, M. A. Corre Professor!!! Lá vem bala!!! - Sobre a Violência na Educação Pública do Paraná. In: FACCI, Marilda G. D.; URT, S. C. Precarização do Trabalho, Adoecimento e Sofrimento do Professor. Teresina: EDUFPI. p. 137-164. 2017.

CHAUÍ, M. Cultura e democracia. 11. ed. São Paulo: Cortez Editora. 2005.

CHRISPINO, A. Gestão do conflito escolar: da classificação dos conflitos aos modelos de mediação. Revista Ensaio: aval. Pol. públ. Edu..,vol.15, n.54, pp.11-28. 2007.

COSTA, M. L. Violência nas Escolas: Contribuições da Psicologia Histórico-Cultural para seu Enfrentamento na Educação. 2014. 211 f. Dissertação (Mestrado em Psicologia). Departamento de Psicologia, Universidade Estadual de Maringá, Maringá. 2014.

ENGELS, F. Obras filosóficas. Tradução de W. Roces. México, FCE. 1986.

FACCI, MGD. Valorização ou Esvaziamento do Trabalho do Professor? Um Estudo Crítico-Comparativo da Teoria do Professor Reflexivo, do Construtivismo e da Psicologia Vygotskyana. Campinas: Autores Associados. 2004.

KOTTAK, C. La Cultura. In: . Antropología Cultural. España: Mc Graw Hill. p. 43-55. 2002.

LOZANO, G. V. El Papel de la Violencia (Marx, Engels y el Marxismo). In: VÁZQUEZ, A. S. E1 mundo de la Violencia. 1a Ed. México: Facultad de Filosofía y letras, 1998.

MALO, M. C. Catolicismo y violencia. In: VÁZQUEZ, A. S. El mundo de la Violencia. 1a Ed. México: Facultad de Filosofía y letras. 1998.

MOLON, S. I. Notas sobre a Constituição do Sujeito, Subjetividade e Linguagem. Revista Psicologia em Estudo. V. 16, n.4, p 613-622, out./dez. 2011.

NOVAIS, F. A. Portugal e Brasil na crise do antigo sistema colonial (1777-1808). São Paulo: Editora Hucitec. 1979.

PLACCO, V. M. N. S. et al. Representações Sociais de jovens sobre a violência e a urgência na formação de professores. Psicologia da Educação, Revista do Programa de Estudos Pós-Graduados PUC-SP, n.14/15, VV.AA - EDUC. 2002.

SOUZA, M. G.; SILVA, V. F. Mediação de Conflitos na Escola. Disciplina Temas especiais em Educação e Sociedade. Taguatinga-DF. 2006. 
SUZUKI, M. A. A Medicalização dos Problemas de Comportamento e da Aprendizagem: Uma Prática Social de Controle. 2012. 174 f. Dissertação(Mestrado)Universidade Estadual de Maringá, Maringá. 2012.

SUZUKI, M. A; LEONARDO, N. S. T. LEAL, Z. F. R. A Medicalização da Educação: Reflexões para a Compreensão e Enfrentamento deste fenômeno. In: Leonardo, N. S. T; LEAL, Z. F; FRANCO, A. F. Medicalização da Educação e Psicologia HistóricoCultural: Em Defesa da Emancipação Humana. Maringá: Eduem. 2017.

VÁZQUEZ, A. S. Praxis y Violencia. In: VÁZQUEZ, A. S. Filosofía de la praxis. 2a. ed. México, Grijalbo. 1980.

VÁZQUEZ, A. S. Ética. Rio de Janeiro: Editora Civilização Brasileira. 2008.

VYGOTSKY, L. S. O Problema do Método. In: A Formação Social da Mente. São Paulo: Martins Fontes. P. 67-88. 1991.

VYGOTSKY, L. S. Pensamento e linguagem. 2. ed. São Paulo: Martins Fontes. 1999.

Recebido em 10 abr 2020.

Publicado em 13 abr 2020.

\footnotetext{
i Doutorando em Psicologia pela Universidade Católica Dom Bosco (UCDB). Mestre em Psicologia pela Universidade Federal do Mato Grosso do Sul (UFMS) - (bolsista Capes). Graduado em Psicologia pela Universidade Católica Dom Bosco (UCDB). Cursando Pedagogia pela Universidade Católica Dom Bosco. Pesquisador nas áreas de Psicologia, Educação, Trabalho e Prática docente, membro do Grupo de Estudos e Pesquisa em Psicologia e Educação/GEPPE do Programa de Pós Graduação em Psicologia e Educação da UFMS. Atuação, como colaborador, no Grupo de Estudos e Pesquisas sobre Formação, Trabalho e Bem-Estar Docente/GEBEM (Cnpq) de maio/2013 à julho/2015 desenvolvido na UCDB. Teve formação complementada pelo programa de bolsas iberoamericanas do Santander em 2015 na Pontifícia Universidad Católica de Chile, Santiago - Chile, desenvolvendo trabalhos em saúde intercultural. Possui experiências com as temáticas: Diagnóstico e Desenho de intervenções em Comunidades, principalmente educativas, Formação e Bem-estar de professores, Enfrentamento da violência na Escola, atendimento clínico em psicologia e Formação do Psicólogo. Atualmente é membro da Associação Brasileira de Ensino de Psicologia (ABEP), núcleo regional do Mato Grosso do Sul e membro da Associação Brasileira de Psicologia Escolar e Educacional (ABRAPEE). Endereço eletrônico: aldenorbsj@gmail.com.

ii É graduada em Psicologia, Pedagogia e Administração de Empresas. Pós-Doutorado pela Unicamp e pela Universidad de Alcalá de Henares - Espanha e Universidade de Lisboa - Portugal. Doutora em Educação com ênfase em Psicologia Educacional pela Universidade Estadual de Campinas (1992). Mestre em Educação (Psicologia da Educação) pela Pontifícia Universidade Católica de São Paulo (1989). Professora Titular Aposentada da UFMS - Universidade Federal de Mato Grosso do Sul. Professora Pesquisadora Sênior dos Programas de Pós-Graduação em Educação e em Psicologia da Universidade Federal de Mato Grosso do Sul. Diretora da ABEP - Associação Brasileira de Ensino de Psicologia em Mato Grosso do Sul e Coordenadora do Grupo de Estudos e Pesquisa em Educação e Psicologia - GEPPE/UFMS. Tem experiência na área de Educação, com ênfase na interface Psicologia e Educação, atuando em ensino, extensão e pesquisa, principalmente com os seguintes temas: Identidade, Aprendizagem, Constituição do Sujeito em Espaços Educativos. Estudos sobre Memória - Personagens/Biografias e Autobiografias na Educação e Psicologia no âmbito regional e nacional. Psicologia e Educação: Contornos e Possibilidades sob o Enfoque das Políticas Públicas/Aporte da Psicologia Histórico-Cultural. Práticas educativas e formativas ( Foco nas questões da violência na escola/ adoecimento psíquico/ práticas de enfrentamento/ suporte do conhecimento psicológico na escola? análises de projetos de formação de professores). Endereço eletrônico: surt@terra.com.br.
} 